\title{
Hubungan Kadar Glukosa Darah Saat Masuk Rumah Sakit Dengan Lama Hari Rawat Pasien Sindrom Koroner Akut (SKA) Di RSUP Dr. M. Djamil Padang
}

\author{
Rosi Oktarina, Yertizal Karani, Zulkarnain Edward
}

\begin{abstract}
Abstrak
Hiperglikemia masih menjadi topik penelitian yang sering dihubungkan dengan kejadian sindrom koroner akut (SKA) di dunia, terutama hiperglikemia saat masuk rumah sakit. Hal ini didasari oleh beberapa pengaruh kadar glukosa darah yang tinggi terhadap sistem kardiovaskuler seperti gangguan fungsi ventrikel kiri, stroke volume yang menurun, regurgitasi katup mitral berulang, gangguan pada waktu pengisian diastolik hingga risiko tinggi untuk arritmia, serta hubungannya dengan peningkatan risiko trombosis. Sehingga semakin memperjelas pengaruh hiperglikemia yang tidak hanya dapat meningkatkan risiko terjadinya SKA, melainkan juga dapat memperburuk kondisi pasien SKA sendiri. Penelitian ini bertujuan mengidentifikasi hubungan kadar glukosa darah sewaktu dengan lama hari rawat pasien Sindrom Koroner Akut (SKA). Jenis penelitian yang digunakan adalah penelitian analitik dengan menggunakan desain penelitian Cross Sectional Study. Penelitian ini menggunakan data sekunder yang diambil di Instalasi Rekam Medik (Medical Record), yakni data rekam medik pasien yang didiagnosis sebagai Sindrom Koroner Akut (SKA) yang dirawat inap di Rumah Sakit Umum Pusat DR. M. Djamil Padang Periode Januari-Desember 2011. Ditemukan sebagian besar pasien SKA masuk rumah sakit dengan kadar Glukosa Darah Sewaktu (GDS) sebesar $\geq$ $200 \mathrm{mg} / \mathrm{dl}(40 \%)$ dan lama hari rawat sebesar $\geq 7$ hari (52\%). Dari hasil analisa bivariat dengan menggunakan uji korelasi Spearman ditemukan adanya hubungan searah antara kadar glukosa darah saat masuk rumah sakit dengan lama hari rawat pasien SKA dengan kekuatan hubungan yang sedang, $r=+0,492, p=0,000(p<0,05)$. Pemantauan terhadap kadar GDS yang diperiksa saat pasien masuk rumah sakit perlu dilakukan dan untuk penelitian yang akan datang diharapkan dapat diteliti lebih lanjut faktor-faktor lain yang mempengaruhi lama hari rawat pasien SKA.
\end{abstract}

Kata kunci: Kadar glukosa darah saat masuk RS, lama hari rawat

\begin{abstract}
Hyperglicemia is still become a research topic which is often associated with the incidence of Acute Coronary Syndrome (ACS) in the world, especially hyperglicemia on hospital admission. This is due to several effects of high random blood glucose to the cardiocasculer system for instance impaired left ventricular function, decreased stroke volume, reccurrent mitral valve regurgitation, impaired diastolic filling, high risk arrhytmias and its corelation with the increase thrombosis risk. This circumstance explains more about the effects of hyperglicemia that not only increase the risk of Acute Coronary Syndrome (ACS), but can also worsen the Acute Coronary Syndrome (ACS) patients condition through a various of mechanisms. This research is purposed to identify the relation between hospital admission blood glucose level with length of stay of Acute Coronary Syndrome (ACS). This research uses analytic research which is using cross sectional design. This research uses secondary data that is taken from the medical records of patients diagnosed as Acute Coronary Syndrome (ACS) admitted to RSUP DR. M. Djamil Padang from January until December 2011. Research found that the most of ACS patients admitted to the hospital with as random blood glucose of $\geq 200$ $\mathrm{mg} / \mathrm{dl}(40 \%)$ and length of stay for $\geq 7$ days (52\%). The results of bivariate analysis by using Spearman correlation test is obtained the correlation between hospital admission blood glucose level to length of stay ACS patients and the strength of correlation is moderate, $r=+0,492, p=0,000(p<0,05)$. The monitoring of random glucose level of ACS patients upon hospitalization is necessary and for future studies the other factors that affect the length of stay of ACS patients should be considered.
\end{abstract}

Keywords:Hospital admission blood glucose, length of stay

Affiliasi penulis : Rosi Oktarina,

Korespondensi :Fakultas Kedokteran Universitas Andalas,

\section{Pendahuluan}

Sindrom koroner akut (SKA) merupakan salah satu manifestasi dari kelainan arteri koroner yang masih menjadi masalah kesehatan utama di dunia. Menurut Data Statistik American Heart Association (AHA) 2008, pada tahun 2005 jumlah penderita yang menjalani perawatan medis di Amerika Serikat akibat SKA hampir mencapai 1,5 juta orang dengan 1,1 juta orang $(80 \%)$ menunjukkan kasus Angina Pektoris Tidak Stabil (APTS) atau Infark Miokard Tanpa Elevasi ST (NSTEMI), sedangkan 20\% kasus tercatat menderita Infark Miokard Dengan Elevasi ST (STEMI). ${ }^{16}$

Hasil dari Jakarta cardiovaskuler study pada tahun 2008 mencatat prevalensi infark miokard pada wanita mencapai $4,12 \%$ dan $7,6 \%$ pada pria, atau 5,29 secara keseluruhan. Angka ini jauh di atas prevalensi infark miokard pada tahun 2000 , yakni hanya $1,2 \%$ saja. Hal ini mendukung hasil survei Departemen Kesehatan RI yang menunjukkan bahwa prevalensi Penyakit Jantung Koroner (PJK) di Indonesia semakin meningkat dari tahun ke tahun ${ }^{7}$

Angka kunjungan pasien akibat PJK di RSUP Dr. M. Djamil Padang sudah mendekati setengah dari keselurahan pasien yang datang ke poliklinik jantung RSUP DR. M. Djamil Padang dengan keluhan 
penyakit jantungnya. Sebuah penelitian retrospektif terhadap peserta askes yang berobat jalan ke bagian Kardiologi RSUP DR. M. Djamil Padang menemukan bahwa $39,75 \%$ dari 4790 pasien penyakit jantung yang berobat jalan adalah penderita PJK. ${ }^{15}$ Laporan tahunan PT ASKES Cabang Sumatera Barat melaporkan kunjungan pasien PJK ke poliklinik Jantung RSUP M. Djamil Padang dari bulan JanuariNovember 1995 berjumlah 8297 orang $(41,6 \%) .{ }^{11}$

Berdasarkan data awal yang diperoleh peneliti dari bagian rekam medik RSUP DR. M. Djamil Padang periode april 2010 - april 2012 diketahui bahwa jumlah pasien Sindrom Koroner Akut (SKA) yang di rawat inap di RSUP DR. M. Djamil Padang mencapai 719 orang $(35,19 \%$ dari 2043 orang) dengan rata-rata lama perawatan berkisar 6-9 hari. Sedangkan angka kunjungan pasien yang berobat jalan ke poliklinik jantung RSUP DR. M. Djamil Padang pada Bulan Desember 2011 mencapai 2503 orang, dan Bulan Desember 2010 masih sekitar 2052 orang. Hal ini semakin menunjukkan bahwa angka kejadian Sindrom Koroner Akut (SKA) di RSUP DR. M. Djamil Padang masih cukup tinggi. ${ }^{3}$

Angka kematian akibat penyakit kardiovaskuler juga cukup tinggi. Menurut data statistik WHO tahun 2008, penyakit jantung iskemik merupakan penyebab utama kematian di dunia $(12,8 \%)$, disusul oleh stroke dan penyakit serebrovaskuler lainnya. ${ }^{19} \mathrm{Di}$ Indonesia, berdasarkan hasil Riskesdas tahun 2007, Penyakit kardiovaskuler yang dalam hal ini penyakit jantung koroner (PJK), meenjadi penyebab kematian terbanyak setelah stroke dan hipertensi. ${ }^{1}$ Profil kesehatan Kota Padang tahun 2010 edisi 2011 melaporkan bahwa penyakit jantung merupakan penyebab kematian terbanyak setelah ketuaan atau orang-orang yang telah lanjut usia, yakni sekitar $20 \%{ }^{2}$

Beberapa studi selama dekade terakhir ini menghubungkan hiperglikemia pada saat masuk rumah sakit dengan angka mortalitas yang semakin tinggi pada pasien dengan sindrom koroner akut (SKA), termasuk Infark Miokard Akut (IMA). ${ }^{10,16}$ Penelitian bagian kardiologi Universitas Indonesia di RSJHK Jakarta juga melaporkan bahwa stress hiperglikemia pada pasien infark miokard akut non DM (Diabetes Melitus) meningkatkan risiko terjadinya gagal jantung dan kematian. ${ }^{12}$

Beberapa efek yang tidak diinginkan dari tingginya kadar glukosa darah pada pasien infark miokard seperti gangguan fungsi ventrikel kiri, stroke volume yang menurun, regurgitasi katup mitral berulang, gangguan pada waktu pengisian diastolik hingga risiko tinggi untuk arritmia menjadi acuan perburukan klinis pada pasien SKA. ${ }^{18}$

Selain itu peningkatan risiko trombosis juga dihubungkan dengan kadar darah yang tinggi saat masuk RS.(4) Sehingga hiperglikemia tidak hanya dapat meningkatkan risiko terjadinya SKA, melainkan juga dapat memperburuk kondisi pasien SKA.

Selain itu, Hiperglikemia saat masuk rumah sakit juga dihubungkan dengan stress hiperglikemia dan menggambarkan respon akut dari keadaan hiperadrenergik. ${ }^{14}$ Keadaan ini merupakan respon tubuh terhadap suatu penyakit dan stres untuk memelihara homeostasis sel dan organ serta sering disebut sebagai hiperglikemia saat kritis. Mekanisme ini akan terus berlanjut melalui aktivasi reaksi inflamasi akibat meningkatnya kadar IL-18 dan CRP di sirkulasi, sehingga akan berujung kepada peningkatan kerusakan pada miokardium itu sendiri. ${ }^{6}$ Keadaan ini tentu dapat meningkatkan risiko kejadian SKA maupun memperburuk klinis pasien dengan SKA.

Dengan demikian, pembuktian secara objektif untuk mengetahui besarnya pengaruh kadar glukosa darah saat masuk rumah sakit dengan lama hari rawat pasien sindrom koroner akut (SKA) masih harus ditinjau kembali. Keteerbatasan penelitian tersebut di wilayah Padang juga semakin memotivasi penulis untuk melakukan penelitian ini, yaitu tentang hubungan kadar glukosa darah saat masuk rumah sakit dengan lama perawatan pasien Sindrom Koroner Akut (SKA) di Rumah Sakit Umum Pusat Dr. M. Djamil Padang.

\section{Metode}

Penelitian dilakukan di Instalasi Rekam Medik (Medical Record) RSUP DR. M. Djamil Padang. Sampel dalam penelitian ini sebanyak 75 orang. Sampel merupakan rekam medik pasien yang didiagnosis sebagai Sindrom Koroner Akut (SKA) yang dirawat inap di RSUP DR. M. Djamil Padang periode januari - desember 2011 yang memenuhi kriteria inklusi dan tidak memiliki kriteria eksklusi. Metode pengambilan sampelnya adalah dengan cara simple random sampling. Data yang diperoleh diolah dengan software computer yaitu SPSS, dan untuk analisis hasil penelitiannya digunakan uji korelasi Spearman dengan tingkat pemaknaan $p<0,05$.

\section{Hasil dan Pembahasan}

a. Kadar Glukosa Darah saat Masuk RS

Tabel 1 : Distribusi Frekuensi Sampel Penelitian Berdasarkan Kadar GDS saat masuk RS

\begin{tabular}{lll}
\hline $\begin{array}{l}\text { Kadar GDS saat } \\
\text { masuk RS (mg/dl) }\end{array}$ & Frekuensi & $\begin{array}{l}\text { Persentase } \\
(\%)\end{array}$ \\
\hline$<140$ & 28 & 37,3 \\
$140-199$ & 17 & 22,7 \\
$\geq 200$ & 30 & 40,0 \\
\hline Total & $\mathbf{7 5}$ & $\mathbf{1 0 0}$ \\
\hline
\end{tabular}

Ket: GDS (Glukosa Darah Sewaktu)

Berdasarkan tabel diatas dapat dilihat bahwa kadar GDS $\geq 200 \mathrm{mg} / \mathrm{dl}$ dan dikategorikan sebagai diabetes melitus sebanyak $40 \%$. Peneitian ini tidak sesuai dengan hasil penelitian Muderspacher et al (2007) yang menyebutkan bahwa sebagian besar pasien SKA masuk dengan kadar GDS yang normal, hanya 13\% dengan kadar GDS yang tinggi. ${ }^{8}$

Pada penelitian juga didapatkan kadar GDS terendah adalah sebesar $68 \mathrm{mg} / \mathrm{dl}$ dan tertinggi 476 $\mathrm{mg} / \mathrm{dl}$. Rata-rata kadar GDS saat masuk RS sebesar $185,86 \pm 81,635 \mathrm{mg} / \mathrm{dl}$.

b. Lama Hari Rawat

Tabel 2 : Distribusi Frekuensi Sampel Penelitian Berdasarkan Lama Hari Rawat

\begin{tabular}{llll}
\hline $\begin{array}{l}\text { Lama } \\
\text { Rawat }\end{array}$ & Hari & Frekuensi & $\begin{array}{l}\text { Persentase } \\
(\%)\end{array}$ \\
\hline $\begin{array}{l}<\quad \text { Median } \\
\text { hari) }\end{array}$ & $(7$ & 36 & 48,0 \\
$\begin{array}{l}\geq \text { Median } \\
\text { hari) }\end{array}$ & $(7$ & 39 & 52,0 \\
\hline Total & & $\mathbf{3 2}$ & $\mathbf{1 0 0}$
\end{tabular}


Berdasarkan tabel diatas dapat dilihat bahwa ditemukan $52 \%$ pasien SKA dirawat inap selama 7 hari lebih, sedangkan $48 \%$ lagi dirawat inap kurang dari 7 hari.

Pada penelitian ini didapatkan lama hari rawat terendah dari pasien SKA yang dirawat inap adalah 2 hari dan terlama adalah 21 hari. Rata-rata lama hari rawat pasien SKA yang menjadi penelitian ini adalah selama 7,43 $\pm 3,688$ hari.

Hasil penelitian ini tidak jauh berbeda dengan data awal dari RSUP DR. M. Djamil Padang periode April 2010 - April 2012 yang dikumpulkan sebelum penelitian ini dilakukan yang menyebutkan bahwa lama hari rawat inap penderita SKA berkisar $6-9$ hari.(3) Begitu juga Penelitian yang dilakukan di salah satu RS di Amerika Serikat bagian Selatan yang melaporkan bahwa rata-rata lama hari rawat penderita infark miokard akut yang merupakan bagian dari SKA adalah $5 \pm 3,7$ hari. ${ }^{(13)}$

c. Hubungan Kadar Glukosa Darah Saat Masuk RS dengan Lama Hari Rawat Pasien SKA Tabel 3 : Hasil Analisis Hubungan Kadar GDS Saat Masuk Rumah Sakit dengan Lama Hari Rawat Pasien SKA

\begin{tabular}{llcc}
\hline & & $\mathbf{R}$ & $\boldsymbol{p}$ \\
\cline { 3 - 3 } Kadar & Lama Hari & $+0,492$ & 0,000 \\
GDS & Rawat & & \\
Saat & Pasien & & \\
Masuk & SKA & & \\
RS & & \\
\hline
\end{tabular}

Dari tabel diatas dapat dilihat bahwa hasil analisa uji statistik menggunakan uji korelasi Spearman pada penelitian ini mendapatkan nilai koefisien korelasi Spearman ( $r$ ) sebesar $+0,492$, yang menunjukkan korelasi positif dengan derajat hubungan yang sedang dengan tarif signifikansi $(p) 0,000(p<0,05)$. Dari hasil analisa uji statistik tersebut dapat disimpulkan bahwa terdapat hubungan yang cukup signifikan antara kadar glukosa darah saat masuk rumah sakit dengan lama hari rawat pasien SKA.

Penelitian ini sejalan dengan salah satu penelitian yang mengemukakan bahwa status diabetes melitus pasien SKA merupakan faktor yang signifikan mempengaruhi lama hari rawat pasien $(p<$ $0,01) .{ }^{5}$ Namun hal ini berbeda dengan penelitian Jenny P. Simpson et al. yang mengemukakan bahwa kadar glukosa darah saat masuk rumah sakit cukup berpengaruh terhadap lama hari rawat pasien infark miokard akut (salah satu manifestasi SKA) dengan nilai $p=0,231(p<0,05, p>0,01)$, namun setelah uji dengan analisis multiple regression variabel yang paling berpengaruh adalah hipertensi dengan nilai $p<$ 0,01 . 13

Pada dasarnya terdapat beberapa mekanisme yang mendasari beberapa pengaruh yang tidak diinginkan dari kadar glukosa darah yang tinggi ini terhadap sistem kardiovaskuler terutama pada pasien SKA, yakni stres oksidatif, aktivasi sistem koagulasi dan platelet, reaksi inflamasi serta disfungsi sel endotel. ${ }^{18}$ Selain itu, kadar glukosa darah yang tinggi saat masuk rumah sakit juga dihubungkan dengan peningkatan risiko thrombosis. ${ }^{4}$ Sehingga kemungkinan peningkatan risiko maupun perburukan klinis pasien SKA akibat kadar glukosa darah yang tinggi ini memang tidak bisa diabaikan begitu saja. Hal inilah yang diduga juga mempengaruhi lama hari rawat pasien SKA baik secara langsung maupun tidak langsung.

Selain menilai hubungan antara kedua variabel tersebut, di dalam penelitian ini juga ditemukan adanya perbedaan rata-rata lama hari rawat pasien SKA yang memiliki kadar glukosa darah saat masuk $R S<140 \mathrm{mg} / \mathrm{dl}, 140-199 \mathrm{mg} / \mathrm{dl}$ dan $\geq$ $200 \mathrm{mg} / \mathrm{dl}$. Rata-rata lama hari rawat pasien SKA dengan kadar glukosa darah saat masuk RS sebesar $\geq 200 \mathrm{md} / \mathrm{dl}$ lebih lama dibandingkan dengan yang lainnya, yakni 9,50 \pm 4,321 hari. Pasien dengan kadar glukosa darah saat masuk RS sebesar < $140 \mathrm{mg} / \mathrm{dl}$ dan 140 - $199 \mathrm{mg} / \mathrm{dl}$ memiliki rata-rata lama hari rawat selama 7,43 $\pm 2,152$ hari dan 6,94 $\pm 2,536$ hari.

Hasil penelitian ini tidak sesuai dengan penelitian yang dilakukan oleh Simpson dan Crane (2005) yang menemukan rata-rata lama hari rawat pasien infark miokard akut yang merupakan bagian dari SKA adalah $7 \pm 4,2$ hari untuk pasien dengan kategori diabetes melitus. ${ }^{13}$ Namun, hasil penelitian ini sesuai dengan hasil penelitian yang pernah dilakukan oleh G. Novo., et al (2009) yang menemukan rata-rata lama hari rawat pasien SKA dengan kategori diabetes melitus tanpa komplikasi mencapai 10,4 $\pm 3,1$ hari, sedangkan untuk pasien SKA kategori diabetes melitus dengan komplikasi rata-rata lama hari rawatnya akan lebih lama, yakni 15,9 $\pm 4,4$ hari. $^{5}$

\section{Kesimpulan}

Berdasarkan penelitian yang telah dilakukan, dapat ditarik kesimpulan bahwa :

1. Rata - rata kadar glukosa darah saat masuk rumah sakit pada pasien SKA adalah 185,86 \pm $81,635 \mathrm{mg} / \mathrm{dl}$ dan ditemukan pasien SKA yang masuk ke dalam kategori diabetes melitus sebanyak 30 orang $(40 \%)$.

2. Rata - rata lama hari rawat pasien SKA adalah $7,43 \pm$ SD 3,688 hari dan ditemukan pasien SKA yang dirawat inap selama 7 hari atau bahkan lebih sebanyak 39 orang (52\%).

3. Terdapat hubungan positif antara kadar glukosa darah saat masuk rumah sakit dengan lama hari rawat pasien SKA di RSUP DR. M. Djamil Padang dengan kekuatan hubungan yang sedang $(r=+0,492, p<0,05)$.

\section{Daftar Pustaka :}

1. Birhasani, 2010. Kadar D-Dimer Plasma pada Penderita Sindrom Koroner Akut dengan Derajat Stenosis Berbeda. Tesis, Universitas Diponegoro Semarang.

2. Dinas Kesehatan Kota Padang, 2011. Profil Kesehatan Kota Padang Tahun 2010 Edisi 2011. Padang.

3. Evyra, 2012. Laporan Satu Tahun Kinerja Pengelola Perawatan Instalasi Pusat Jantung RSUP Dr. M. Djamil Padang Periode April 2011 - April 2012. Padang.

4. Firman, Doni, Fadilah S., Idris Idham, 2007. Glukosa Darah Puasa Sebagai Prediktor Kejadian Kardiovaskuler Pasca Sindrom Koroner Akut pada Penderita Diabetes Melitus. Artikel Penelitian Bagian Kardiologi FK Universitas Indonesia/RSJHK, Jakarta.

5. G, Novo, Scordato F, Cerruto G., Vitale G., Ciaramitaro G., et al.,2009. In Hospital Stay of Patient with Acute Coronary Syndrome with or without Diabetes Melitus. Minerva Cardioangiologica; 57 (2): 159-64. 
6. Marfella, Raffaele, et al, 2003. Effects of Stress Hyperglikemia on Acute Miocard Infarction. Diabetes Care; 26,11;Proquest:3129.

7. Melati, Rima, Endang Basuki, Budhi Setianto, 2008. Relationship Between Job Strain and Myocardial Infarction in The National Cardiovascular Center Patient. Jurnal Kedokteran Indonesia; 29: 12-19.

8. Mudespacher, Damaris, et al, 2007. Admission Glycaemia and Outcome in Patients with Acute Coronary Syndrome. Diabetes and Vascular Disease Research; 4: 346.

9. Najmah, 2011. Managemen dan Analisa Data Kesehatan. Yogyakarta : Nuha Medika.

10. P., Sahibzada, Khan AA., Sahibzada WA., 2009. The Impact of Hiperglicaemia on Morbidity and Acute Myocardial Infarction. Journal of Ayub Abbottabad Jan Mar; 21(1): 110-5.

11. PT ASKES Indonesia. 1995. Laporan Tahunan PT ASKES Cabang Sumbar. Padang.

12. Sani, Murthado, 2007. Hiperglikemia dan Prognosis Infark Miokard Akut pada penderita tanpa Diabetes Melitus. Artikel Penelitian Bagian Kardiologi FK Universitas Indonesia/RSJHK, Jakarta.

13. Simpson, Jenny P., Crane Patricia B, 2005. The Effects of Hyperglycemia on Patient Length of Stay Following Myocardial Infarction. Medsurg Nursing-ProQuest; 14(4): 233.
14. Sinnaeve, Peter $R$ et al, 2009. Association of Elevated Fasting Glucose with Increased Short-Term and 6-Month Mortality in STSegment Elevation Acute Coronary Syndrome. ArchIntern Med; 169(4): 402-409.

15. Saharman, Leman, 1994. Masalah Kardiovaskuler di RSUP Dr. M. Djamil Padang dalam Penatalaksanaan Pelayanan Media terhadap Kasus-kasus yang Banyak pada Peserta ASKES PT PERSERO, ASKES Kantor Cabang Sumatea Barat.

16. Suryanti, Enny, 2010. Perbedaan Rerata Kadar Kolesterol antara Penderita Angina Pektoris Tidak Stabil, Infark Miokard Tanpa ST Elevasi, dan Infark Miokard Dengan ST Elevasi pada Serangan Akut. Surakarta. Skripsi, FK Universitas Muhamadiyah Surakarta.

17. Thalib, Lukman et al, 2011. Impact of Diabetic Status on the Hyperglicemia-induced Adverse Risk of Short Term Outcomes in Hospitalized Patient with Acute Coronary Syndrome in Finding from the Gulf Registry of Acute Coronary Events (Gulf RACE). Clinical Medicine and Research; 9 (1) : 32-37.

18. Undas, Anetta, Ilena wiek, Ewa Stepien, Krzysztof Zmudka, Wieslawa Tracz, 2008. Hyperglicemia is Associated with Enhanced Thrombin Formation, Platelet Activation and Fibrin Clot Resistance to Lysis in Patients with Acute Coronary Syndrome. Diabetes Care;31,8;Proquest:1590.

19. WHO, 2011. The Top Ten Causes of Death 2008. Diakses tanggal 10 Desember 2011.

20. http://www.who.int/whr/. 